Hypothesis

\title{
Visualising the Experimentally Uncharted Territories of Membrane Protein Structures inside Protein Data Bank
}

\author{
Wei $\operatorname{Li}^{1}{ }^{1}$ (D) \\ 1 Institute of Special Environmental Medicine, Nantong University, No. 9, Seyuan Road, Nantong City, \\ Jiangsu Province, P. R. China; wli148@aucklanduni.ac.nz \\ * Correspondence: wli148@aucklanduni.ac.nz;
}

\begin{abstract}
As of January 13, 2020, there is not any direct report yet of the degree to which missing residues exist for experimentally determined membrane protein (MP) structures, which constitute more than half of current drug targets. With a chain- and position-specific $v$ isualisation and a statistical analysis of all MP structures inside PDB (as of September 25, 2019), this article argues that the experimentally uncharted territories (EUTs, i.e., consisting of missing residues) within PDB are pluggable and should be plugged with an experimental data-driven hybrid approach, and calls for continued development of MP structural determination with less and less EUTs, in light of MPs' crucial role in biological and biomedical research, both fundamental and pharmaceutical.
\end{abstract}

Keywords: Position-Specific Visualization; Experimentally Uncharted Territories; Membrane Protein Structure; Protein Data Bank

\section{Introduction}

As cellular gate-keepers, membrane proteins (MPs) account for a third of the eukaryotic proteome and are responsible for a variety of physiological functions [1-4]. For instance, cells use MPs to transmitt signals into cells, transport ions and molecules, bind to cell surface or a substrate, and catalyze reactions under different conditions [5-8].

Established in 1971 [9,10], Protein Data Bank (PDB) is the global repository for experimentally obtained biomolecular structural data, constituting an enormously valuable resource for research across the biological and biomedical sciences [11-16]. With the advent of novel biophysical tools for MP structural biology, the past decade saw a rapid increase in the number of experimentally determined MP structures [17-26]. This new structural knowledge has expanded our understanding of their action mechanism [27-30], and contributed to rational drug design, too [8,31-34].

\section{Motivation}

In original PDB-format data, the experimentally determined atomic coordinates are presented in the ATOM records. Chances are that they do not exactly match the sequence (consisting of nucleic and/or amino acid residues) of the experimental sample per se, be it protein, DNA, RNA or their complexes with drugs and/or other small molecules [35-37]. In fact, this misalignment arises from the uncharted territories (i.e., missing residues) of MP experimental structures deposited in PDB. In structural biology, hole is usually used to describe a pore or a cavity in a biomolecular structure, like the hydrophilic lumen of Cav1.1 and Cav1.2 [26,27]. Thus, experimentally uncharted territory (EUT) is used instead to describe the experimentally undermined parts/regions (i.e., missing residues) of MP structures, the size of an EUT is defined as the number of residues whose atomic coordinates 
3

are not experimentally determined and therefore missing in the original PDB-format data. Here, an N- or C-terminal flanking EUT is defined as an EUT which includes the $\mathrm{N}$ - or the C-terminal of a protein. Otherwise, it is called an interior or non-flanking EUT here. Take Cav1.1 as an example, which is the first (as of January 13, 2020) L-type voltage-dependent $\mathrm{Ca}^{2+}$ channels (VDCCs), whose structure was experimentally determined to a resolution of $3.6 \AA$ with cryo-electron microscopy (cryo-EM) [26,38]. With a sequence alignment [39] and a close inspection of the PDB files (PDB IDs: 5GJV and 5GJW), two interior EUTs in the Cav1.1 cryo-EM structures stood out, one with 358 residues ( $19.11 \%)$ and another with 119 residues (6.35\%), compared to the entire length (1873) of Cav1.1 [26]. For another instance, residues 4247-4277 are not experimentally determined in the recently reported cardiac ryanodine receptor 2 (RyR2) cryo-EM structure [29], compared to the previously reported RyR2 sequences [40].

As of January 13,2020, a total of 159230 biomolecular structures have been deposited in the Protein Data Bank [10,41]. Among the 156365 (98.20\% of 159230) biomolecular structures ( as of September $25,2019)$ in PDB [10,41], MPs are of extraordinary functional interest due to their role in a variety of physiological functions [1-4]. Of further structural significance is EUTs in the transmembrane (TM) region and/or in the structurally proximity of the binding and action sites of drug(s) or its interacting partner(s), as such an EUT might mislead the subsequent experimental investigation into drugs' action mechanism from a structural point of view, making it even more complicated and challenging and thus even pricier for novel drugs to be developed using their traditional counterparts' structure-activity relationships [27]. Taken together, there is not any direct report yet of the degree to which MP EUTs exist throughout the 48-year-old PDB [9], of which this article aims to present a statistical analysis, visualization and overall assessment.

\section{Statistical analysis of the MP EUTs}

As of September 25, 2019, there are a total of 9666 (supplementary file PDB1.kiwi) experimentally determined MP (associated with 2498 ligands) structures in PDB, accounting for approximately $6.16 \%$ of all 156365 biomolecular structures in PDB [10,41]. Of the 9666, supplementary file brief.pdf includes a statistical update as of September 25, 2019.

As shown in Table 1, while the MP structural determination is intact (i.e., no missing residue) for only 1841 among the $9666 \mathrm{MPs}$, and a large part $(75.57 \%$, Table 1$)$ of the chains in the MP structures are with EUTs (i.e., with missing residue), the number of missing MP residues accounts only for a small part $(7.79 \%$, Table 1$)$ of all MP residues of the 9666 .

\begin{tabular}{|l|l|l|l|l|}
\hline Protein level & Variable & MPs & MPs with EUTs & Ratio \\
\hline & Value & 9666 & 7825 & $80.95 \%$ \\
\hline Chain level & Variable & MP chains & MP chains with EUTs & Ratio \\
\hline & Value & 32001 & 24186 & $75.57 \%$ \\
\hline Residue level & Variable & MP residues & missing MP residues & Ratio \\
\hline & Value & 10641563 & 829656 & $7.79 \%$ \\
\hline
\end{tabular}

Table 1. Statistical analysis of the MP EUTs within PDB as of September 25, 2019.

$$
\text { Vis }
$$

66 Visualizing the MP EUTs inside PDB

To ensure reproducibility, Table 2 outlines the entire computational analysis step by step.

In Figures 1, 2 and 3, each missing MP residue is marked as a tiny blue point according to its PDB ID, its chain ID and its sequence-specific position (i.e., Residue ID), while each maximum Residue ID is marked as a red point, and each and every MP chain is represented as a straight line perpendicular 


\begin{tabular}{|c|l|l|l|}
\hline Step & Input file & Python script command & Output file(s) \\
\hline 1 & PDB1.kiwi & RCSB.py & 9666 PDB files \\
\hline 2 & 9666 PDB files & second.py & hole.neu \\
\hline 3 & hole.neu & third.py & third.out \\
\hline 4 & third.out & fourth.py & fourth.out \\
\hline 5 & fourth.out & fifth.py 1 10000 & Figure 1 \\
\hline 6 & fourth.out & fifth.py 10000 20000 & Figure 2 \\
\hline 7 & fourth.out & fifth.py 20000 24186 & Figure 3 \\
\hline 8 & fourth.out & histogram.py & Figure 4 \\
\hline
\end{tabular}

Table 2. Computational analysis of the MP EUTs within PDB. In this table, all files and python scripts (excluding the 9666 PDB files) are submitted as supplementary files.

to $x$-axis. In case its structural determination is intact, it is represented as just one red point at the top of a white straight line perpendicular to $x$-axis. Otherwise, the positions of all missing MP residues are marked by a series of blue points under that red point along the white straight line perpendicular to x-axis. In other words, in Figures 1, 2 and 3, the area under all red points represents all MP sequences as of September 25, 2019, in which the white area is the experimentally charted territory, while the blue area is the experimentally uncharted territory. Collectively, Figures 1,2 and 3 put forward a visual update of the accumulation of MP EUTs inside PDB during the past decade, highlighting a need towards MP structural determination with less and less EUTs, considering their roles in a variety of physiological functions [1-4], as above discussed.

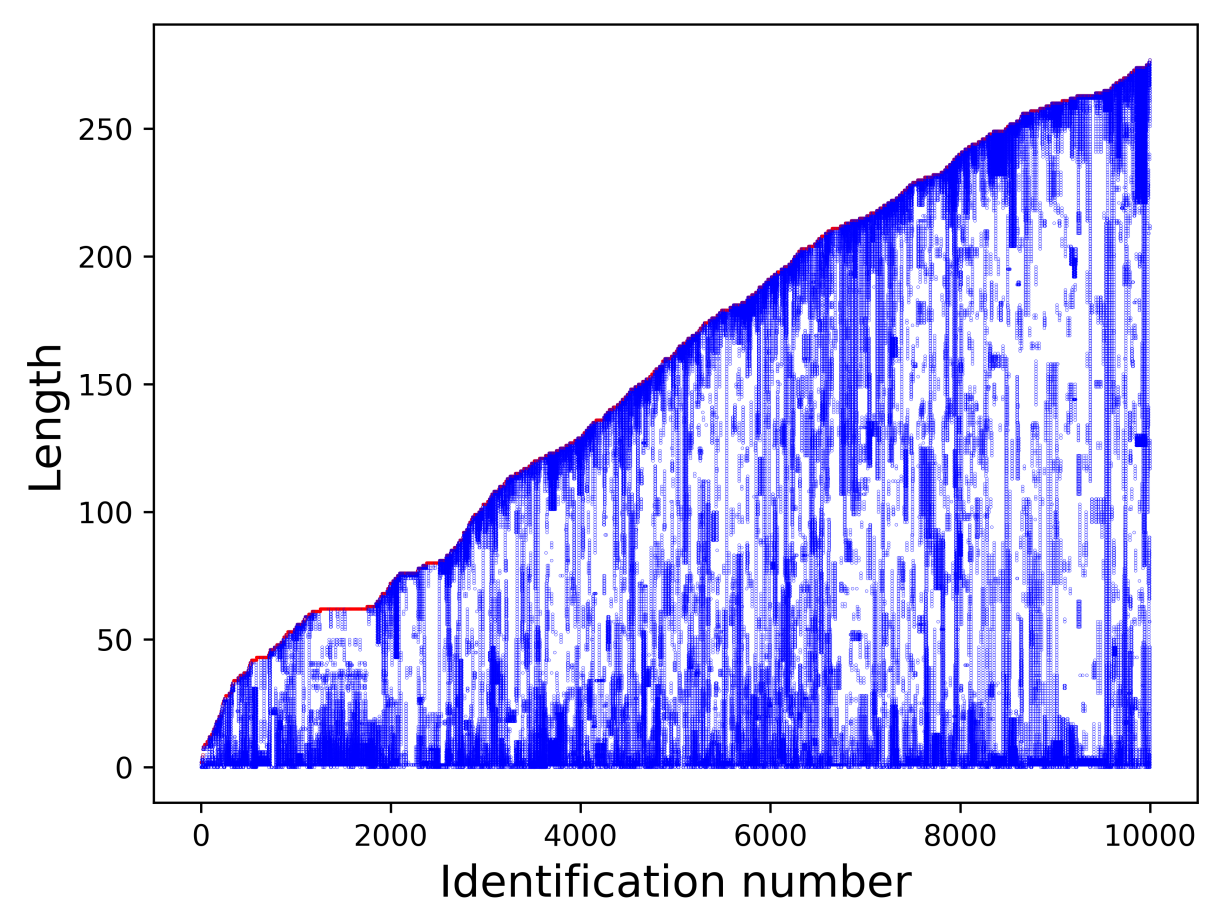

Figure 1. Chain- and sequence position-specific visualization of the MP EUTs within PDB as of September 25, 2019. This figure accounts for the first 10000 among the 24186 (Table 1) chains of MPs with EUTs (fourth.out in Table 2).

Nevertheless, Figures 1, 2 and 3 might be misleading in that the size of a blue point (denoting one missing residue) is much wider than the width of a column corresponding to a single MP chain, leading to a slightly distorted illustration of the white area, i.e., the experimentally charted territory. Unfortunately, this issue is not easy to resolve, because if the X-axis is to be enlarged so that each 


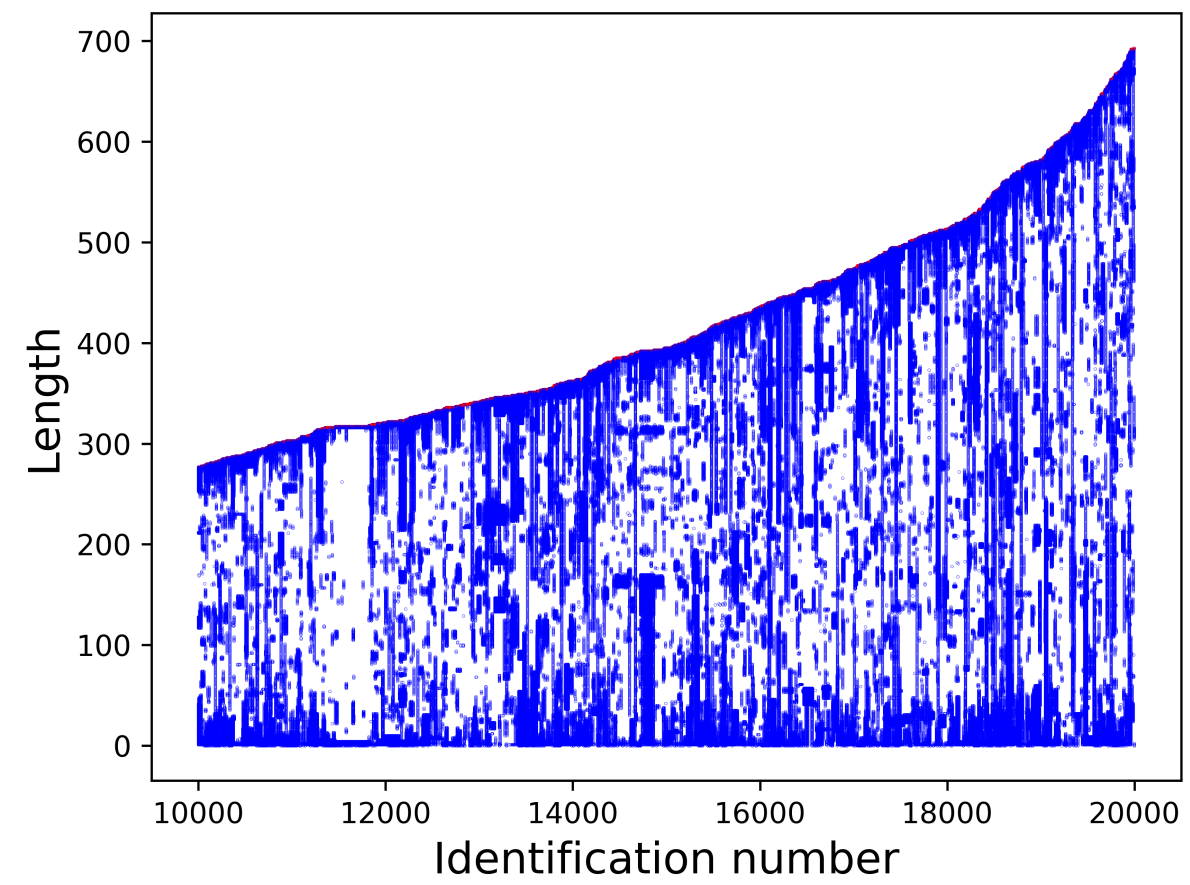

Figure 2. Chain- and sequence position-specific visualization of the MP EUTs within PDB as of September 25, 2019. This figure accounts for the second 10000 among the 24186 (Table 1) chains of MPs with EUTs (fourth.out in Table 2).

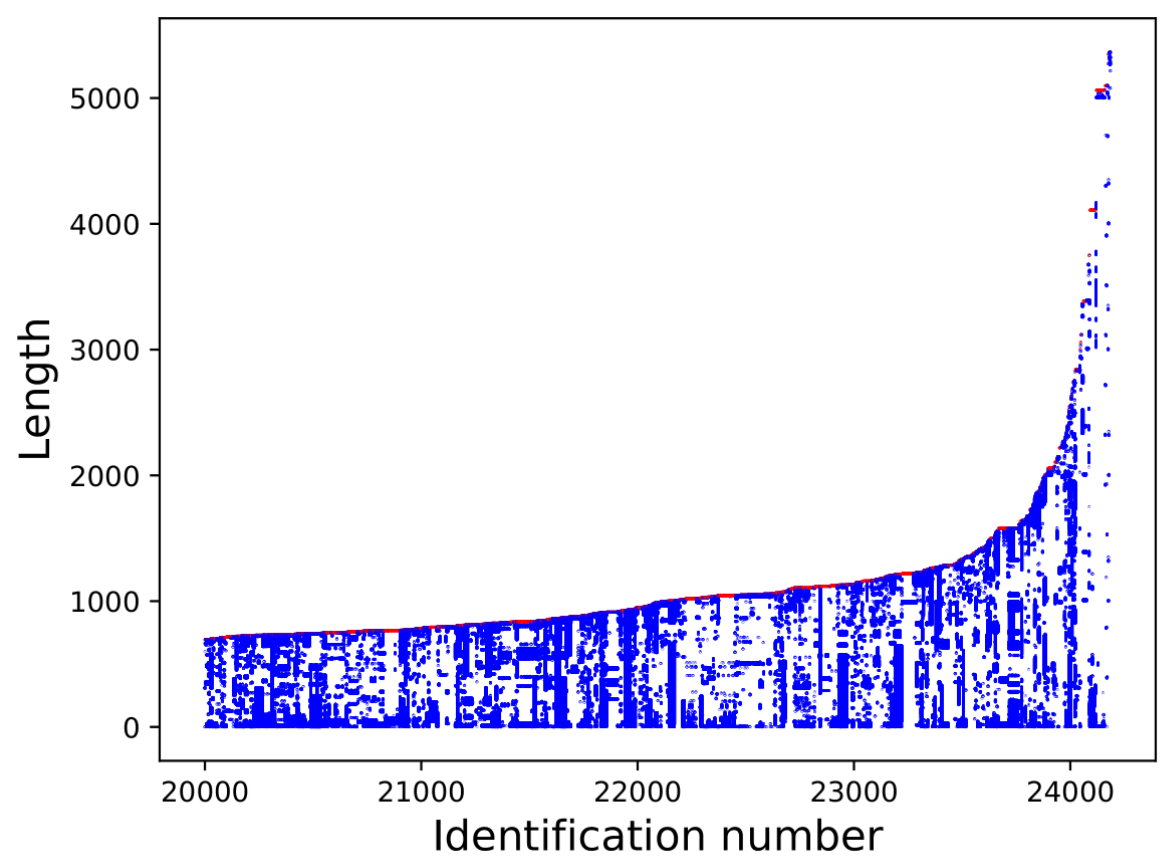

Figure 3. Chain- and sequence position-specific visualization of the MP EUTs within PDB as of September 25, 2019. This figure accounts for the last 4186 among the 24186 (Table 1) chains of MPs with EUTs (fourth.out in Table 2). 
structure is represented with the width of a blue point, that would lead to way too many figures to reach an accurate overall assessment of MP EUTs in the whole PDB.

From Figure 4, it can be seen that the EUT sizes range from 1 to $\sim 1200$, and that most EUTs $(97.30 \%)$ are with a size of less than $200 \mathrm{MP}$ residues. Notwithstanding, no evidence can be drawn from Figure 4 that the MP EUTs are negligible and harmless for subsequent functional investigation of MPs' roles in the life of a cell. Instead, Figure 4, along with Figures 1,2 and 3, calls for MP structural determination with less and less EUTs, too.

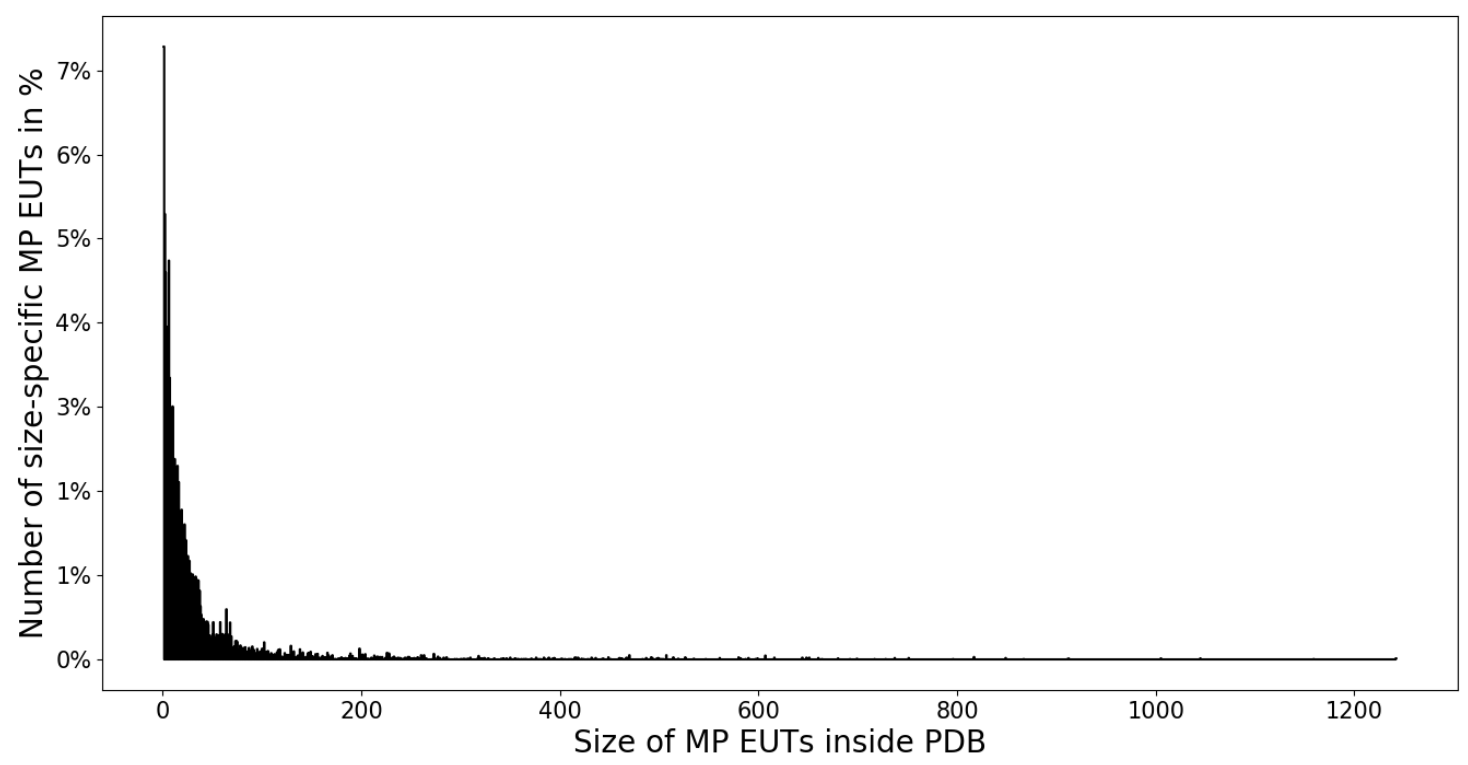

Figure 4. A histogram of the size-specific distribution of the MP EUTs within PDB.

\section{Conclusion and Discussion}

The past decade of MP structural determination saw the gradual accumulation of MP EUTs within PDB [42-48], reaching a point where it is increasingly reasonable, if not pressing, for MP structures to be experimentally determined in an EUT-less manner .

1. MP EUTs within PDB do matter. The experimental determination of MP structures is usually achieved through lengthy and laborious experimental efforts and expensive tools [36,49,50]. On one hand, MP EUTs harms the integrity of the hard-earned biomolecular structural data within PDB [36,51-54]. On the other, it is possible that MP EUTs misleads fundamental investigation into current drugs' action mechanism when they are structurally located at the proximity of the drugs' binding binding site.

2. In general, the existence of the EUTs in PDB could be attributed to the technical limitations of the biophysical tools and/or difficult sample (intrinsically disordered proteins for instance) [55-59] during experimental data acquisition.

3. Technically, MP EUTs are pluggable and should be plugged an experimental data-driven hybrid approach [60-73]. In other words, the continued development of PDB with less and less MP EUTs within is within the reach of currently available tools, experimental and computational. After almost half a century since the launch of PDB [9], the time is now ripe for this aim to be included on the structural biology development agenda.

4. While the focus here is MP EUTs within the 48-year-old PDB [9], case-specifically, it is more informative to map MP EUTs to MP structures, and closely examine the spatial positions of the missing residues), as it allows us to find out whether the EUTs actually reside in the structural proximity of the binding/action sites of conventional drugs/potential drug candidates or not, 
towards an intact picture of MPs' roles (as more than half of current drug targets) in the life of a cell.

Author Contributions: Cconceptualization, W.L.; methodology, W.L.; software, W.L.; validation, W.L.; formal analysis, W.L.; investigation, W.L.; resources, W.L.; data curation, W.L.; writing-original draft preparation, W.L.; writing-review and editing, W.L.; visualization, W.L.; supervision, W.L.; project administration, W.L.; funding acquisition, not applicable.

Funding: This research received no external funding.

Acknowledgments: I am grateful for the whole community of structural biologists and biophysicists, who have contributed to the continued development of PDB during the past 48 years.

Conflicts of Interest: The author declares no conflict of interest.

1. Raman, P.; Cherezov, V.; Caffrey, M. The Membrane Protein Data Bank. Cellular and Molecular Life Sciences 2005, 63, 36-51. doi:10.1007/s00018-005-5350-6.

2. Hardy, D.; Bill, R.M.; Jawhari, A.; Rothnie, A.J. Overcoming bottlenecks in the membrane protein structural biology pipeline. Biochemical Society Transactions 2016, 44, 838-844. doi:10.1042/bst20160049.

3. Kozma, D.; Simon, I.; Tusnády, G.E. PDBTM: Protein Data Bank of transmembrane proteins after 8 years. Nucleic Acids Research 2012, 41, D524-D529. doi:10.1093/nar/gks1169.

4. von Heijne, G. The membrane protein universe: what's out there and why bother? Journal of Internal Medicine 2007, 261, 543-557. doi:10.1111/j.1365-2796.2007.01792.x.

5. Overington, J.P.; Al-Lazikani, B.; Hopkins, A.L. How many drug targets are there? Nature Reviews Drug Discovery 2006, 5, 993-996. doi:10.1038/nrd2199.

6. Bordner, A.J. Predicting protein-protein binding sites in membrane proteins. BMC Bioinformatics $2009,10$. doi:10.1186/1471-2105-10-312.

7. Rask-Andersen, M.; Almén, M.S.; Schiöth, H.B. Trends in the exploitation of novel drug targets. Nature Reviews Drug Discovery 2011, 10, 579-590. doi:10.1038/nrd3478.

8. Yin, H.; Flynn, A.D. Drugging Membrane Protein Interactions. Annual Review of Biomedical Engineering 2016, 18, 51-76. doi:10.1146/annurev-bioeng-092115-025322.

9. Crystallography: Protein Data Bank. Nature New Biology 1971, 233, 223-223. doi:10.1038/newbio233223b0.

10. Berman, H.; Henrick, K.; Nakamura, H. Announcing the worldwide Protein Data Bank. Nature Structural E Molecular Biology 2003, 10, 980-980. doi:10.1038/nsb1203-980.

11. Fine, J.; Chopra, G. Lemon: a framework for rapidly mining structural information from the Protein Data Bank. Bioinformatics 2019. doi:10.1093/bioinformatics/btz178.

12. Liu, Y.; Xu, Z.; Yang, Z.; Chen, K.; Zhu, W. A knowledge-based halogen bonding scoring function for predicting protein-ligand interactions. Journal of Molecular Modeling 2013, 19, 5015-5030. doi:10.1007/s00894-013-2005-7.

13. The RCSB Protein Data Bank: views of structural biology for basic and applied research and education. Nucleic Acids Research 2014, 43, D345-D356. doi:10.1093/nar/gku1214.

14. Tsuji, T.; Yoda, T.; Shirai, T. Deciphering Supramolecular Structures with Protein-Protein Interaction Network Modeling. Scientific Reports 2015, 5. doi:10.1038/srep16341.

15. Colbes, J.; Corona, R.I.; Lezcano, C.; Rodríguez, D.; Brizuela, C.A. Protein side-chain packing problem: is there still room for improvement? Briefings in Bioinformatics 2016, p. bbw079. doi:10.1093/bib/bbw079.

16. RCSB Protein Data Bank: Enabling biomedical research and drug discovery. Protein Science 2019. doi:10.1002/pro.3730.

17. Ishchenko, A.; Abola, E.E.; Cherezov, V. Crystallization of Membrane Proteins: An Overview. In Methods in Molecular Biology; Springer New York, 2017; pp. 117-141. doi:10.1007/978-1-4939-7000-1_5.

18. Miao, J.; Ishikawa, T.; Robinson, I.K.; Murnane, M.M. Beyond crystallography: Diffractive imaging using coherent x-ray light sources. Science 2015, 348, 530-535. doi:10.1126/science.aaa1394.

19. Miao, Y.; Cross, T.A. Solid state NMR and protein-protein interactions in membranes. Current Opinion in Structural Biology 2013, 23, 919-928. doi:10.1016/j.sbi.2013.08.004. 
20. Li, J.; Shang, G.; Chen, Y.J.; Brautigam, C.A.; Liou, J.; Zhang, X.; chen Bai, X. Cryo-EM analyses reveal the common mechanism and diversification in the activation of RET by different ligands. eLife 2019, 8 . doi:10.7554/elife.47650.

21. chen Bai, X.; McMullan, G.; Scheres, S.H. How cryo-EM is revolutionizing structural biology. Trends in Biochemical Sciences 2015, 40, 49-57. doi:10.1016/j.tibs.2014.10.005.

22. Hong, M.; Zhang, Y.; Hu, F. Membrane Protein Structure and Dynamics from NMR Spectroscopy. Annual Review of Physical Chemistry 2012, 63, 1-24. doi:10.1146/annurev-physchem-032511-143731.

23. Freedberg, D.I.; Selenko, P. Live Cell NMR. Annual Review of Biophysics 2014, 43, 171-192. doi:10.1146/annurev-biophys-051013-023136.

24. Fink, A.; Sal-Man, N.; Gerber, D.; Shai, Y. Transmembrane domains interactions within the membrane milieu: Principles, advances and challenges. Biochimica et Biophysica Acta (BBA) - Biomembranes 2012, 1818, 974-983. doi:10.1016/j.bbamem.2011.11.029.

25. Neutze, R.; Brändén, G.; Schertler, G.F. Membrane protein structural biology using X-ray free electron lasers. Current Opinion in Structural Biology 2015, 33, 115-125. doi:10.1016/j.sbi.2015.08.006.

26. Wu, J.; Yan, Z.; Li, Z.; Qian, X.; Lu, S.; Dong, M.; Zhou, Q.; Yan, N. Structure of the voltage-gated calcium channel Cav1.1 at $3.6 \AA$ A resolution. Nature 2016, 537, 191-196.

27. Li, W.; Shi, G. How Cav1.2-bound verapamil blocks $\mathrm{Ca}^{2+}$ influx into cardiomyocyte: Atomic level views. Pharmacological Research 2019, 139, 153-157. doi:10.1016/j.phrs.2018.11.017.

28. Ghosh, E.; Nidhi, K.; Shukla, A.K. SnapShot: GPCR-Ligand Interactions. Cell 2014, 159, 1712-1712.e1. doi:10.1016/j.cell.2014.12.008.

29. Gong, D.; Chi, X.; Wei, J.; Zhou, G.; Huang, G.; Zhang, L.; Wang, R.; Lei, J.; Chen, S.R.W.; Yan, N. Modulation of cardiac ryanodine receptor 2 by calmodulin. Nature 2019, 572, 347-351. doi:10.1038/s41586-019-1377-y.

30. Phillips-Jones, M.K. Structural and biophysical characterisation of membrane protein-ligand binding. Biochimica et Biophysica Acta (BBA) - Biomembranes 2014, 1838, 1-2. doi:10.1016/j.bbamem.2013.09.013.

31. Zhao, Y.; Huang, G.; Wu, J.; Yan, N. Rabbit Cav1.1-Nifedipine Complex, 2019. doi:10.2210/pdb6jp5/pdb. 32. Schenone, M.; Dančík, V.; Wagner, B.K.; Clemons, P.A. Target identification and mechanism of action in chemical biology and drug discovery. Nature Chemical Biology 2013, 9, 232-240. doi:10.1038/nchembio.1199.

33. Wells, J.A.; McClendon, C.L. Reaching for high-hanging fruit in drug discovery at protein-protein interfaces. Nature 2007, 450, 1001-1009. doi:10.1038/nature06526.

34. Lagerström, M.C.; Schiöth, H.B. Structural diversity of G protein-coupled receptors and significance for drug discovery. Nature Reviews Drug Discovery 2008, 7, 339-357. doi:10.1038/nrd2518.

35. Crunkhorn, S. Role of the Protein Data Bank. Nature Reviews Drug Discovery 2019, 18, 98-98. doi:10.1038/d41573-019-00010-1.

36. How Structural Biologists and the Protein Data Bank Contributed to Recent FDA New Drug Approvals. Structure 2019, 27, 211-217. doi:10.1016/j.str.2018.11.007.

37. Ali AM, Atmaj J, V.O.N.G.M.D.A. Stapled Peptides Inhibitors: A New Window for Target Drug Discovery. Computational and Structural Biotechnology Journal 2019, 17, 263-281. doi:10.1016/j.csbj.2019.01.012.

38. Catterall, W.A. International Union of Pharmacology. XLVIII. Nomenclature and Structure-Function Relationships of Voltage-Gated Calcium Channels. Pharmacological Reviews 2005, 57, 411-425.

39. Sievers, F.; Wilm, A.; Dineen, D.; Gibson, T.J.; Karplus, K.; Li, W.; Lopez, R.; McWilliam, H.; Remmert, M.; Söding, J. Fast, scalable generation of high-quality protein multiple sequence alignments using Clustal Omega. Molecular Systems Biology. 2011, 7, 539-543.

40. Brohus, M.; Søndergaard, M.T.; Chen, S.R.W.; van Petegem, F.; Overgaard, M.T. Ca ${ }^{2+}$-dependent calmodulin binding to cardiac ryanodine receptor (RyR2) calmodulin-binding domains. Biochemical Journal 2018, 476, 193-209. doi:10.1042/bcj20180545.

41. Leman, J.K.; Ulmschneider, M.B.; Gray, J.J. Computational modeling of membrane proteins. Proteins: Structure, Function, and Bioinformatics 2014, 83, 1-24. doi:10.1002/prot.24703.

42. Validation of Structures in the Protein Data Bank. Structure 2017, 25, $1916-1927$. doi:10.1016/j.str.2017.10.009.

43. Protein Data Bank (PDB): The Single Global Macromolecular Structure Archive. In Methods in Molecular Biology; Springer New York, 2017; pp. 627-641. doi:10.1007/978-1-4939-7000-1_26.

44. Velankar, S.; Best, C.; Beuth, B.; Boutselakis, C.H.; Cobley, N.; Silva, A.W.S.D.; Dimitropoulos, D.; Golovin, A.; Hirshberg, M.; John, M.; Krissinel, E.B.; Newman, R.; Oldfield, T.; Pajon, A.; Penkett, 
C.J.; Pineda-Castillo, J.; Sahni, G.; Sen, S.; Slowley, R.; Suarez-Uruena, A.; Swaminathan, J.; van Ginkel, G.; Vranken, W.F.; Henrick, K.; Kleywegt, G.J. PDBe: Protein Data Bank in Europe. Nucleic Acids Research 2009, 38, D308-D317. doi:10.1093/nar/gkp916.

45. Möckel, C.; Kubiak, J.; Schillinger, O.; Kühnemuth, R.; Corte, D.D.; Schröder, G.F.; Willbold, D.; Strodel, B.; Seidel, C.A.M.; Neudecker, P. Integrated NMR, Fluorescence, and Molecular Dynamics Benchmark Study of Protein Mechanics and Hydrodynamics. The Journal of Physical Chemistry B 2018, 123, 1453-1480. doi:10.1021/acs.jpcb.8b08903.

46. López, C.A.; Swift, M.F.; Xu, X.P.; Hanein, D.; Volkmann, N.; Gnanakaran, S. Biophysical Characterization of a Nanodisc with and without BAX: An Integrative Study Using Molecular Dynamics Simulations and Cryo-EM. Structure 2019. doi:10.1016/j.str.2019.03.013.

47. Wagner, J.; Schaffer, M.; Fernández-Busnadiego, R. Cryo-electron tomography-the cell biology that came in from the cold. FEBS Letters 2017, 591, 2520-2533. doi:10.1002/1873-3468.12757.

48. Forneris, F.; Burnley, B.T.; Gros, P. Ensemble refinement shows conformational flexibility in crystal structures of human complement factor D. Acta Crystallographica Section D Biological Crystallography 2014, 70, 733-743. doi:10.1107/s1399004713032549.

49. Kinjo, A.R.; Bekker, G.J.; Suzuki, H.; Tsuchiya, Y.; Kawabata, T.; Ikegawa, Y.; Nakamura, H. Protein Data Bank Japan (PDBj): updated user interfaces, resource description framework, analysis tools for large structures. Nucleic Acids Research 2016, 45, D282-D288. doi:10.1093/nar/gkw962.

50. Blundell, T.L. Protein crystallography and drug discovery: recollections of knowledge exchange between academia and industry. IUCrJ 2017, 4, 308-321. doi:10.1107/s2052252517009241.

51. Hu, T.; Sprague, E.R.; Fodor, M.; Stams, T.; Clark, K.L.; Cowan-Jacob, S.W. The impact of structural biology in medicine illustrated with four case studies. Journal of Molecular Medicine 2017, 96, 9-19. doi:10.1007/s00109-017-1565-x.

52. OneDep: Unified wwPDB System for Deposition, Biocuration, and Validation of Macromolecular Structures in the PDB Archive. Structure 2017, 25, 536-545. doi:10.1016/j.str.2017.01.004.

53. Worldwide Protein Data Bank biocuration supporting open access to high-quality 3D structural biology data. Database 2018, 2018. doi:10.1093/database/bay002.

54. Renaud, J.P.; Chari, A.; Ciferri, C.; ti Liu, W.; Rémigy, H.W.; Stark, H.; Wiesmann, C. Cryo-EM in drug discovery: achievements, limitations and prospects. Nature Reviews Drug Discovery 2018, 17, 471-492. doi:10.1038/nrd.2018.77.

55. Isaksson, L.; Mayzel, M.; Saline, M.; Pedersen, A.; Rosenlöw, J.; Brutscher, B.; Karlsson, B.G.; Orekhov, V.Y. Highly Efficient NMR Assignment of Intrinsically Disordered Proteins: Application to B- and T Cell Receptor Domains. PLOS ONE 2013, 8, e62947. doi:10.1371/journal.pone.0062947.

56. Baul, U.; Chakraborty, D.; Mugnai, M.L.; Straub, J.E.; Thirumalai, D. Sequence Effects on Size, Shape, and Structural Heterogeneity in Intrinsically Disordered Proteins. The Journal of Physical Chemistry B 2019. doi:10.1021/acs.jpcb.9b02575.

57. Nielsen, J.T.; Mulder, F.A.A. Quality and bias of protein disorder predictors. Scientific Reports $2019,9$. doi:10.1038/s41598-019-41644-w.

58. Martinelli, A.; Lopes, F.; John, E.; Carlini, C.; Ligabue-Braun, R. Modulation of Disordered Proteins with a Focus on Neurodegenerative Diseases and Other Pathologies. International Journal of Molecular Sciences 2019, 20, 1322. doi:10.3390/ijms20061322.

59. Booth, P.J.; Curran, A.R. Membrane protein folding. Current Opinion in Structural Biology 1999, 9, $115-121$. doi:10.1016/s0959-440x(99)80015-3.

60. Steven, A.C.; Baumeister, W. The future is hybrid. Journal of Structural Biology 2008, 163, $186-195$. doi:10.1016/j.jsb.2008.06.002.

61. Joosten, R.P.; Salzemann, J.; Bloch, V.; Stockinger, H.; Berglund, A.C.; Blanchet, C.; Bongcam-Rudloff, E.; Combet, C.; Costa, A.L.D.; Deleage, G.; Diarena, M.; Fabbretti, R.; Fettahi, G.; Flegel, V.; Gisel, A.; Kasam, V.; Kervinen, T.; Korpelainen, E.; Mattila, K.; Pagni, M.; Reichstadt, M.; Breton, V.; Tickle, I.J.; Vriend, G. PDB_REDO: automated re-refinement of X-ray structure models in the PDB. Journal of Applied Crystallography 2009, 42, 376-384. doi:10.1107/s0021889809008784.

62. Joosten, R.P.; Vriend, G. PDB Improvement Starts with Data Deposition. Science 2007, 317, $195-196$. doi:10.1126/science.317.5835.195. 
63. Yin, H.; Slusky, J.S.; Berger, B.W.; Walters, R.S.; Vilaire, G.; Litvinov, R.I.; Lear, J.D.; Caputo, G.A.; Bennett, J.S.; DeGrado, W.F. Computational Design of Peptides That Target Transmembrane Helices. Science 2007, 315, 1817-1822. doi:10.1126/science.1136782.

64. van Beusekom, B.; Touw, W.G.; Tatineni, M.; Somani, S.; Rajagopal, G.; Luo, J.; Gilliland, G.L.; Perrakis, A.; Joosten, R.P. Homology-based hydrogen bond information improves crystallographic structures in the PDB. Protein Science 2017, 27, 798-808. doi:10.1002/pro.3353.

65. Miles, A.J.; Wallace, B.A. Circular dichroism spectroscopy of membrane proteins. Chemical Society Reviews 2016, 45, 4859-4872. doi:10.1039/c5cs00084j.

66. Mesarich, C.H.; Schmitz, M.; Tremouilhac, P.; McGillivray, D.J.; Templeton, M.D.; Dingley, A.J. Structure, dynamics and domain organization of the repeat protein Cin1 from the apple scab fungus. Biochimica et Biophysica Acta (BBA) - Proteins and Proteomics 2012, 1824, 1118-1128. doi:10.1016/j.bbapap.2012.06.015.

67. Debiec, K.T.; Whitley, M.J.; Koharudin, L.M.; Chong, L.T.; Gronenborn, A.M. Integrating NMR, SAXS, and Atomistic Simulations: Structure and Dynamics of a Two-Domain Protein. Biophysical Journal 2018, 114, 839-855. doi:10.1016/j.bpj.2018.01.001.

68. Perilla, J.R.; Zhao, G.; Lu, M.; Ning, J.; Hou, G.; Byeon, I.J.L.; Gronenborn, A.M.; Polenova, T.; Zhang, P. CryoEM Structure Refinement by Integrating NMR Chemical Shifts with Molecular Dynamics Simulations. The Journal of Physical Chemistry B 2017, 121, 3853-3863. doi:10.1021/acs.jpcb.6b13105.

69. Shimada, I.; Ueda, T.; Kofuku, Y.; Eddy, M.T.; Wüthrich, K. GPCR drug discovery: integrating solution NMR data with crystal and cryo-EM structures. Nature Reviews Drug Discovery 2018, 18, 59-82. doi:10.1038/nrd.2018.180.

70. Selenko, P. Quo Vadis Biomolecular NMR Spectroscopy? International Journal of Molecular Sciences 2019, 20, 1278. doi:10.3390/ijms20061278.

71. Nugent, T. De Novo Membrane Protein Structure Prediction. In Methods in Molecular Biology; Springer New York, 2014; pp. 331-350. doi:10.1007/978-1-4939-1465-4_15.

72. Tinberg, C.E.; Khare, S.D.; Dou, J.; Doyle, L.; Nelson, J.W.; Schena, A.; Jankowski, W.; Kalodimos, C.G.; Johnsson, K.; Stoddard, B.L.; Baker, D. Computational design of ligand-binding proteins with high affinity and selectivity. Nature 2013, 501, 212-216. doi:10.1038/nature12443.

73. Lounkine, E.; Keiser, M.J.; Whitebread, S.; Mikhailov, D.; Hamon, J.; Jenkins, J.L.; Lavan, P.; Weber, E.; Doak, A.K.; Côté, S.; Shoichet, B.K.; Urban, L. Large-scale prediction and testing of drug activity on side-effect targets. Nature 2012, 486, 361-367. doi:10.1038/nature11159. 